\title{
A COMPARATIVE CASE STUDY OF BIO-BASED MATERIAL DEVELOPMENT BY DESIGNERS USING A DIY APPROACH IN A CIRCULAR CONTEXT
}

\author{
Charlotte ASBJøRN SÖRENSEN and Therese ROSÉN \\ School of Art and Communication (K3), Malmö University, Malmö, Sweden
}

\begin{abstract}
There is an essential visionary element to design that affects how we experience and shape our environment. Reacting to our current reality with climate change and exceeding our planetary boundaries, designers are increasingly involved as catalysers of innovative and interdisciplinary material research by generating alternative proposals and scenarios for more sustainable futures. Recent academic literature on material practices within design has revealed a lack of strategies to support designers during the different stages of developing bio-based materials when using a DIY approach. Earlier studies have shown that the most successful material designers strategically gathered knowledge through literature, systematic material experiments and external expertise. The choice of strategy was related to prior experience and the material designers' level of education. This paper suggests a strategy based on a comparative case study combined with a contextual literature review. The bio-based materials in this study are produced by using local resources; they promote sustainability, are placed in a circular context and underlines the importance of the connection between a context, a community and the designer. Material-driven design practices, applying DIY approaches to material development processes combined with a theoretical framework from circular design and sustainable development can provide entry points to address parts of the complexity and envision new alternative solutions. Conclusions aim to encourage designers, researchers and tutors to respond to emerging needs by re-thinking material practices in design.
\end{abstract}

Keywords: DIY-materials, material-driven design practices, sustainability, design education, circular economy

\section{INTRODUCTION}

There is an essential visionary element to design that affects how we experience and shape our environment. Reacting to our current reality with climate change and exceeding our planetary boundaries, designers are increasingly involved as catalysers of innovative and interdisciplinary material research by generating alternative proposals and scenarios for more sustainable futures. Design is fundamental to all human activity, and at the nexus of values, attitudes, needs, and actions, designers can act as transdisciplinary integrators and facilitators [1]. Buchanan [2] stated that "designers deal with possible worlds and with opinions about what the parts and the whole of the human environment should be". Material designers have the opportunity for contributing to the societal change towards increased sustainability and circular economy. Materials are continuously developed, adapted and experimented with by material professionals (engineering, material science, biochemistry etc.) around the globe. In recent years, design has contributed to material development through Material-driven design practices, applying DIY approaches to material development processes or as a funded research collaboration with industry. The inspiration comes from various sources such as a specific problem that needs to be solved, an available waste stream, a bio-based building block, or an abundance of a renewable resource. Material-driven design practices and the DIY approach to developing materials find a significant source of creativity from transgressing norms concerning how materials are processed and used or what is considered a material source [3].

There is broad recognition that knowledge production in higher education is shifting from traditional disciplinary questions to cross-disciplinary investigations grounded in industry, society and the environment [4]. The challenge is to mix 'codified, discipline-based (explicit) knowledge' from outside 
an applied field with 'intuitive (implicit) knowledge' from within it [5]. This challenge can be an issue in applied research projects conducted by designers and students experienced primarily in design practice [4]. Material-driven design and the DIY approach to developing materials have been applied in design education to support multiple perspectives on materials and support design students in developing reflective material practices, bridging theory and practice [6]. Earlier studies have shown that the most successful material designers strategically gathered and utilised knowledge both from literature, systematic material experiments and by using their network to find external expertise [ 7 \& 8]. The choice of strategy was related to prior experience and the material designers' level of education. This study suggests a strategy supporting designers when applying DIY approaches to the material development processes of bio-based materials. The study is based on a contextual review combined with a comparative case study focusing on bio-based materials suitable for craft-based or small-scale manufacturing. The selected bio-based materials are produced by using local resources; they promote sustainability, are placed in a circular context and underlines the importance of the connection between a context, a community and the designer.

\section{COMPARATIVE CASE STUDY}

Comparative case studies embody a deep knowledge of a subject and lie at the crossroads of practise and theory. When selecting cases for the study, the following criteria were considered crucial; the biobased materials should be produced using local resources; promote sustainability and be placed in a circular context. The six bio-based materials (Figure 1.) in the comparative case study are developed by 2nd and 3rd years BA Design students. The 2nd year students developed their bio-based materials in the course Material Driven Design 7.5 ECTS for 5 weeks. The 3rd year students developed their materials as part of their thesis work (30 ECTS). As it was considered important to study more mature bio-material concepts in-depth, these six projects were selected from a total of 49 projects.

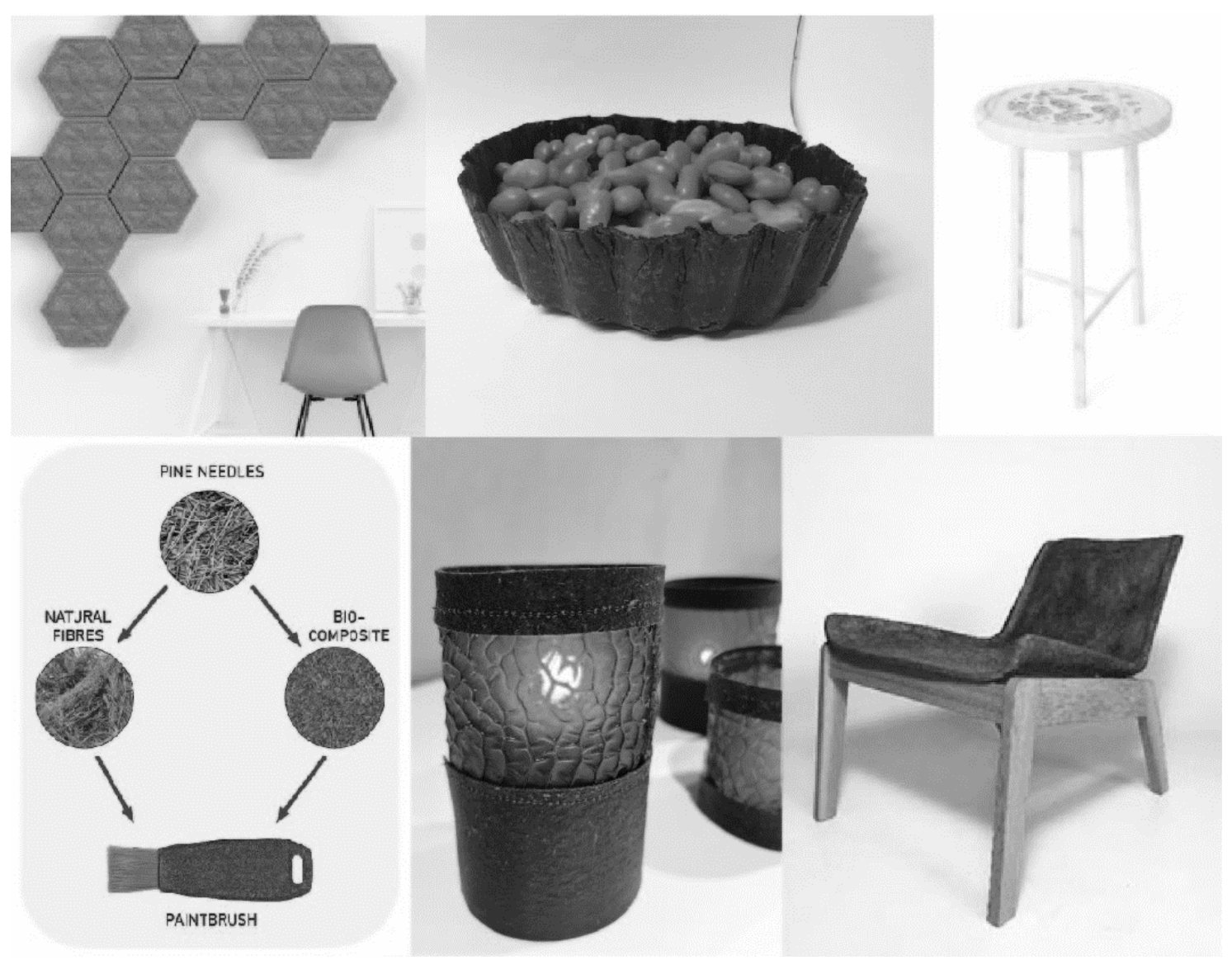

Figure 1. Bio-based materials developed by 2nd and 3rd years B.A. level design students. Top row: Rose panels (Therese Rosén \& Jonna Kytölä), Argenti Flex (Emma Thyni), SeaBuckthorn composite (Peder Nilsson). Lower row: Pine needles (Jonas Hagberth \& Neriman Arif), Argenti Flex \& Coffee Chaff (Emma Thyni), Residue chair (Hanna Carlsson) 
A comparative case study [9] of the project documentation was conducted. In the first step, commonalities of the collected cases were noted as well as distinct differences. The informants answered clarifying questions before coding the material. The material was then coded top-down and bottom-up and resulted in 7 main categories. See results in Table 1. Within each category, skills, activities and knowledge input and output were identified and summarised in short descriptions.

Table 1. Results from the comparative case study

\begin{tabular}{|c|c|}
\hline Category & Description of findings \\
\hline Explore \& define a context & $\begin{array}{l}\text { Allows for the designer to position the project, } \& \text { thereby to in-depth explore } \& \text { develop } \\
\text { sustainable \&/or circular solutions. } \\
\text { A well-defined context contributes to an active framing } \& \text { re-framing process during the } \\
\text { material development process. }\end{array}$ \\
\hline A Working Hypothesis & $\begin{array}{l}\text { Facilitate active use of theoretical knowledge, especially the tinkering stage. } \\
\text { Offers focus \& allow for in-depth knowledge creation. }\end{array}$ \\
\hline Theoretical knowledge & $\begin{array}{l}\text { In-depth knowledge of specific raw materials pervades the projects, i.e., biochemistry, } \\
\text { technical, botanical, historical \& cultural aspects. } \\
\text { Theoretical understanding of theories from sustainability, circular economy \& the } \\
\text { current system surrounding the raw material or waste stream played a key role } \\
\text { throughout the process. }\end{array}$ \\
\hline Practical skills & $\begin{array}{l}\text { Material processing \& tinkering skills with biobased components are connected to the } \\
\text { ability to translate or adapt industrial-scale manufacturing techniques \& cooking } \\
\text { techniques to the lab environment. } \\
\text { The ability to analyse \& utilise the biochemical components of, e.g., an apple or pine } \\
\text { needles are crucial when developing viable biomaterials. }\end{array}$ \\
\hline $\begin{array}{l}\text { Experiential \& Aesthetical } \\
\text { characterisation }\end{array}$ & $\begin{array}{l}\text { User feedback allows for understanding, adjusting \& fine-tuning the materials sensorial } \\
\text { qualities \& aesthetic expression. } \\
\text { Contributes to define application area \& position the final material in a system }\end{array}$ \\
\hline Testing \& Validation & $\begin{array}{l}\text { Basic technical tests are performed continuously. } \\
\text { More advanced \& accurate testing is typically performed when scaling up the volume of } \\
\text { the material. Initially, the testing is done by the designer \& later on, external tests \& } \\
\text { validation are considered necessary. }\end{array}$ \\
\hline Storytelling & $\begin{array}{l}\text { Used as an ideation method in the concept development stage and when envisioning } \\
\text { possible future circular scenarios. } \\
\text { Translating complex information so non-experts "get it" at a glance, thereby bridging the } \\
\text { knowledge barriers between stakeholders \& society. }\end{array}$ \\
\hline
\end{tabular}

\section{CONTEXTUAL LITERATURE REVIEW}

A contextual review [4] was conducted to identify bio-based materials developed by designers using a DIY-materials approach and have been further developed to be made commercially available. The following selection criteria were applied in the review; bio-based materials produced by using local resources; promote sustainability and are placed in a circular context. In the next step, the list was reduced to contain only the materials where verified background information could be identified that described the development process. Academic sources were prioritised over articles in design magazines and forums, popular science, newspapers and commercial sources. Finally, 10 bio-based materials and their development processes were selected to be further studied to find common denominators, see Figure 2. 


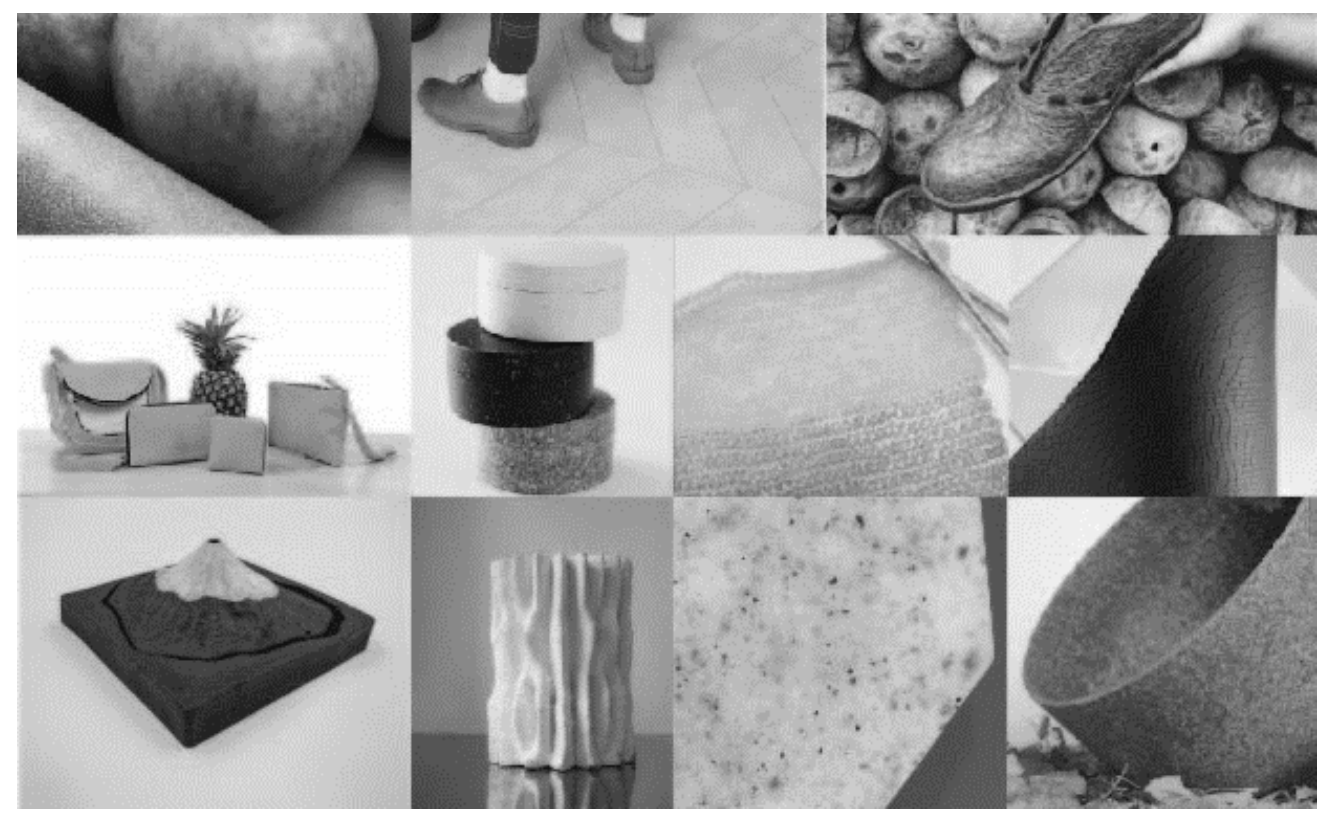

Figure 2. From top left to bottom right: Apple leather (Beyond Leather Materials ApS.), Mogu floor (Officina Corpuscoli), Malai (Malai Biomaterials Design Pvt.Ltd.), Pinatex (Ananas Anam), Sulapac Premium (Sulapac Oy.), Bioyarn (AlgiKnit Ltd.), Fruitleather Mango (Fruitleather Rotterdam), Mount Fuji (Ground Rule Studio), Neo lonic (Blast Studio), Salt panels \& $L A A B$ lampshades (MIYUCA)

The common denominators of the materials found in the contextual review were collaboration across scientific, technological, social, ecological, academic and business fields. The materials had, in general, taken 4-8 years to develop from a concept stage to become upscaled commercially available. Designers had initially created the selected materials; however, two main categories could be identified:

- $\quad$ start-up design companies with designers controlling the material development through all stages, often acting as a project manager and company director with external partners/ expertise

- funded research collaboration with industry and inter- or transdisciplinary cooperation between design, material science and manufacturing process development

In the second category, most designers were doctoral students with previous experience of the DIYmaterial approaches and Material Driven Design. The selected materials were primarily represented by the first category, which was expected due to selection criteria.

\section{FINDINGS}

Working within a field of high complexity, in the cross-section between disciplines and with different expertise and skillsets required during the development process, requires a strategy that breaks down the complexity into manageable stages. The adequate combination of theoretical knowledge, skills, methods and approaches are unique for each specific bio-based material development process using a DIY approach. Yet a general strategy can be identified once the processes studied in the comparative case study has been broken down into stages. The model is based on the findings from the comparative case study and the contextual literature review. Each stage shown in the illustration (see Figure 2) needs to be adapted to fit the specific project. The model contains three circles, and they represent (1) required skills, (2) knowledge in- or output and (3) area of activities. The model illustrates how these relate to each other when developing a bio-based material using a DIY approach. 


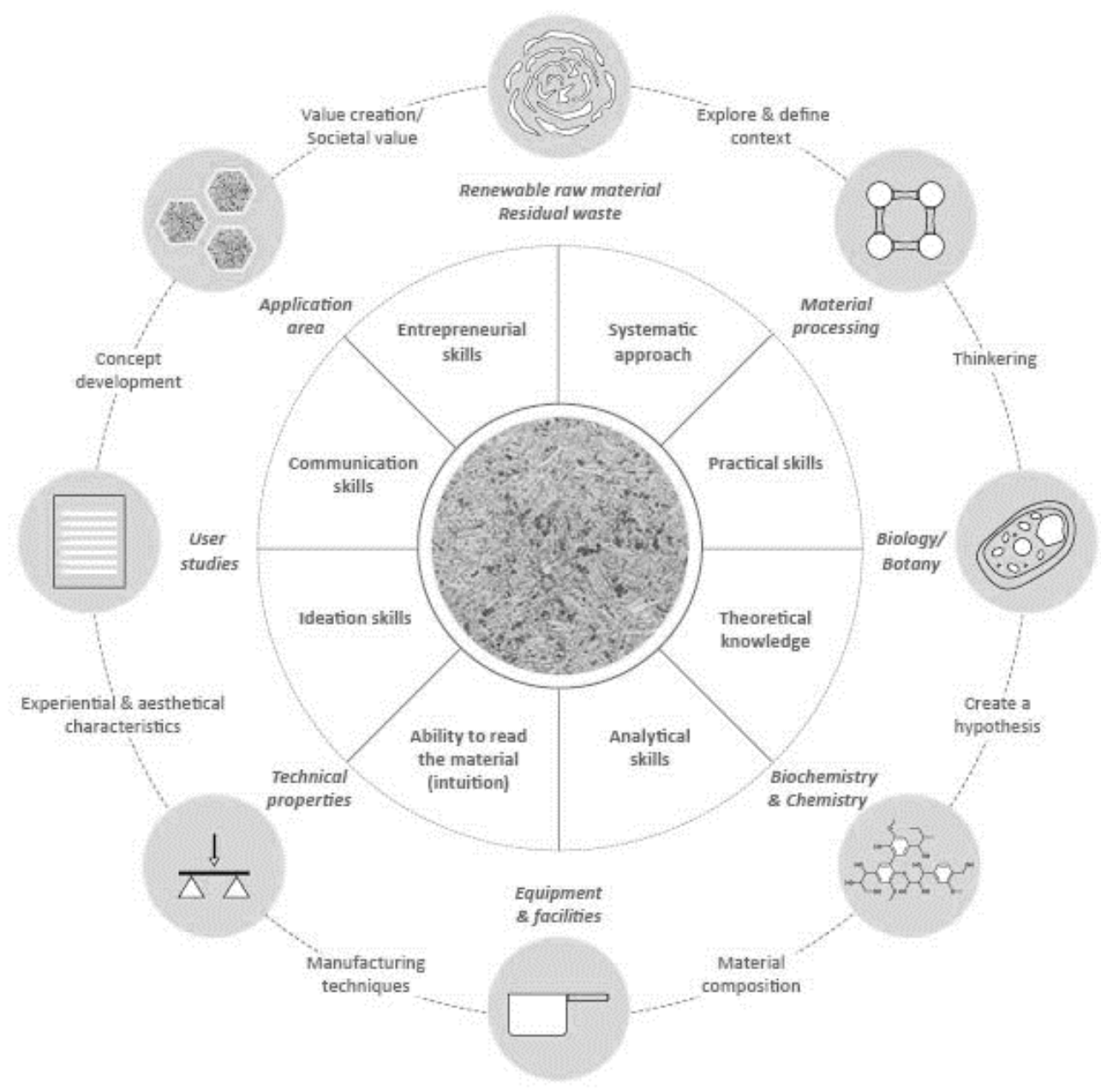

Figure32. The model contains three circles, and they represent (1) required skills, (2) knowledge in- or output and (3) area of activities in the project when developing a bio-based material, using a DIY approach

\section{Discussions}

The biggest challenge for both students and designers was making the most out of many data types and mixing scientific with phenomenological methodology. The ability to continuously analyse and be "in dialogue" with or "read" the material proved crucial in the first development phase. Reflection became an integrated activity during the experimental stages. The ability to utilise theoretical knowledge, access to equipment and practical skills influenced the quality of the developed processing process or the cultivation of the material. Scaling up and formalising the manufacturing process of the material brings a new dimension to the relationship between designer, technologies, and the material. The process involves new stakeholders and competencies in a project. Communication skills and entrepreneurial skills become crucial factors for succeeding as it is no longer enough with tempting pictures of material samples in social media when developing a business. At this stage, storytelling becomes an efficient tool in communicating sensorial qualities and technical properties to non-designers and mastering technical language become essential when communicating with engineering.

Carmen Alvarez Hijosa [10] points out that by moving between the world of business and academia when developing Pinatex, it became perfectly acceptable to pose challenging questions, to doubt, ponder and follow thoughts that may lead nowhere today but somewhere tomorrow. The questions are becoming crossroads where crucial decisions can be made, building the foundations for a better and more in-depth way of thinking and doing. When analysing the student projects, it became clear that the complexity of working with the DIY approach in a material-driven design process improved their ability to frame and re-frame problems during the material development process. Ingold's theories [11] on framing and enskillment in how to frame, contextualise and re-frame a problem connect well with Simon's notion 
[12] of how to develop intuitive expertise; both skills are needed when developing a reflective material practice. Intuitive expertise grows out of reflective practices as defined in Schön's theories [13\&14]. Reflection-in-action, reflection-on-action and knowing-in-action is strongly connected to the practice of tinkering in an academic context and contributes to bridging the gap between theory and practice in current design education [6].

\section{CONCLUSIONS}

The model developed in the study underlines the importance of the connection between context, community and the designer when applying DIY approaches to material development processes. The result indicates that a synthesis between disciplinary and real-world knowledge production, including collaboration between academics and non-academics, led to the most successful results, both amongst students and professional designers. Transdisciplinary is highly recommended when scaling up the production from craft-based production to small-scale manufacturing, however challenging, as it crosses disciplinary and academic boundaries.

\section{REFERENCES}

[1] Wahl D. and Baxter S. The designer's role in facilitating sustainable solutions. Design Issues, 2008, 24.2, pp.72-83.

[2] Buchanan R. Rhetoric, humanism, and design. Discovering Design: Explorations in design studies, 1995, (23) pp.23-66.

[3] Barati B. and Karana E. Affordances as materials potential: What design can do for materials development. International Journal of Design. 2019, 13.3, pp.105-123.

[4] Barnes C. and Melles G. Managing interdisciplinarity: a discussion of the contextual review in design research. In International Association of Societies of Design Research (IASDR) Conference. 2007.

[5] Griffiths R. Knowledge production and the research-teaching nexus: the case of the built environment disciplines. Studies in Higher Education, 2004, 29(6), pp.709-726.

[6] Asbjørn Sörensen C. A Material Framework for Product Design, Doctoral Thesis. 2018 (Faculty of Engineering and Department of Design Sciences, Lund University, Lund)

[7] Asbjørn Sörensen C. and Thyni E. A qualitative study of the challenges faced by material designers when developing DIY-materials. DS 104: Proceedings of the 22nd International Conference on Engineering and Product Design Education. 2020 (Design Society, Herning).

[8] Kääriäinen P. and Rueda Mejía S. Experimental Wood-based Materials. Emerging Materials \& Technologies: New approaches in Design Teaching Methods in four exemplified areas. 2020, (Franco Angeli Design International s.r.l., Milano) pp. 29-51.

[9] Gibbs G. R. Analysing qualitative data. (U. Flick, Red.) 2008. (Sage Publications Ltd., London)

[10] Alvarez Hijosa C. Pinatex, the design development of a new sustainable material - Doctoral Thesis. 2014. (Royal College of Art, London)

[11] Ingold T. The temporality of the landscape. World Archaeology, (2). 1993, pp. 152.

[12] Simon H. A. What is an "explanation" of behaviour? Psychological Science, 3(3), 1992, pp. 150161.

[13] Schön D. A. The reflective practitioner: How professionals think in action. 1983. (Ashgate Publishing Limited. U.K)

[14] Schön D. A. Designing as reflective conversation with the materials of a design situation. Knowledge-Based Systems. 5(1), 1992, pp. 3-14. 